\title{
Parásitos y pelos: historias de la selva de Chamela
}

\author{
Carmen Guzmán Cornejo y Angel Herrera Mares
}

\begin{abstract}
Resumen
El parasitismo es una forma común de vida dentro de la naturaleza, sin embargo, los parásitos pocas veces son incluidos como parte de la diversidad biológica. Dependiendo de su ubicación, estos pueden clasificarse en dos grupos, los endoparásitos, aquellos que viven dentro del cuerpo de un huésped, y los ectoparásitos que se encuentran sobre o por fuera de él. Aquí citamos algunos ejemplos de ectoparásitos habitantes del pelo de la piel de los mamíferos, y contamos cómo es un día de trabajo en una reserva de la biosfera localizada en el Pacífico mexicano, dedicada a la recolección y al estudio de estos parásitos. Actualmente, en donde existe una crisis ambiental y de salud, el trabajo taxonómico representa una de las bases más importantes para conocer lo que se quiere preservar.
\end{abstract}

Palabras clave: ectoparásitos, mamíferos, Rickettsia spp., reserva de la biosfera.

\section{Parasites and hairs: stories from the Chamela forest}

\begin{abstract}
Parasitism is a common way of life in nature, however, parasites are rarely included as part of biological diversity. Depending on their location, these can be classified as: endoparasites, those who live inside the body of a host, and ectoparasites, those found on or outside the host. Here we cite some examples of ectoparasites inhabiting mammalian skin and describe a workday to collect them in a Biosphere reserve located in the Mexican Pacific. In these times where there is an environmental and health crisis, taxonomic work represents one of the most important bases for knowing what we want to preserve.
\end{abstract}

Keywords: ectoparasites, mammals, Rickettsia spp., biosphere reserve.

Recepción: 24/04/2020. Aprobación: 04/02/2021. Dol: http://doi.org/10.22201/cuaieed.16076079e.2021.22.3.2 


\section{Carmen Guzmán Cornejo}

Realizó sus estudios de licenciatura, maestría y doctorado en la unAm. Actualmente es profesora de carrera titular B de tiempo completo en el Laboratorio de Acarología de la Facultad de Ciencias de la UNAM. Imparte clases a nivel licenciatura de Biología de Animales I y Parasitología General y forma parte del Sistema Nacional de Investigadores. Además, es autora de diversos artículos de investigación, de libros y de capítulos de libros; así como de artículos de divulgación, todos enmarcados en temas relacionados con la taxonomía y la diversidad de endoparásitos y ectoparásitos de vertebrados.

\section{Angel Herrera Mares}

angelmares@ciencias.unam.mx orcid.org/0000-0002-2610-1139

Biólogo y maestro en ciencias formado en el Laboratorio de Acarología de la Facultad de Ciencias. Actualmente es estudiante de doctorado en el Laboratorio de Ecología de Enfermedades y Una Salud de la Facultad de Medicina Veterinaria y Zootecnia. Ha sido profesor de asignatura en la Facultad de Ciencias y su principal interés es la taxonomía de ácaros asociados a mamíferos pequeños y medianos, así como los aspectos macroecológicos dentro del sistema ácaro-roedor-bacteria. 


\section{Parásitos y pelo en lugares poco comunes}

En la naturaleza existe una gran variedad de especies de animales, de bacterias, de hongos y hasta de plantas que viven como parásitos. El parasitismo es una asociación donde existen un parásito que se aloja y se alimenta de un huésped, y dependiendo de su ubicación, estos parásitos pueden clasificarse en endoparásitos, aquellos que viven dentro del huésped, y ectoparásitos, los cuales se encuentran sobre o por fuera de él.

Algunos ectoparásitos, llamados temporales, utilizan a su huésped como si fuera un hotel, viven sólo por un corto periodo de tiempo sobre él, se alimentan intermitentemente o usan al huésped momentáneamente para poder a parearse; mientras que los otros, los permanentes, consideran al huésped su hogar y hacen todas estas actividades sobre él por el resto de sus vidas.

Losectoparásitos pueden utilizar comohuéspedesaanimalesinvertebrados (que no tienen columna vertebral), como por ejemplo a arañas, alacranes, ciempiés, grillos y hasta a otros ectoparásitos como chinches besuconas. Sin embargo, lo más común es hallarlos sobre diferentes animales vertebrados (que tienen vértebras y un esqueleto como el nuestro).

Quizá lo primero que pensamos cuando escuchamos la palabra "ectoparásitos" sean las pulgas y las garrapatas de nuestras mascotas, pero en realidad hay un mundo de pequeños organismos que viven entre las escamas de los reptiles, las plumas de las aves y hasta en la piel lisa o granulosa de los anfibios. Aunque, sin duda, los que viven en la piel de los mamíferos son los más conocidos.

El pelo es una característica única de los mamíferos, algunos lo presentan abundantemente por todo el cuerpo y otros sólo en algunas partes específicas. Tiene diferentes funciones, por ejemplo, puede ser un receptor táctil como en el caso de las vibrisas de los gatos (los llamados "bigotes"), una protección como en el caso de las "espinas" del puercoespín o puede funcionar como aislamiento contra el frío o el calor como la lana de los borregos (Martin et al., 2001). La piel, además, representa un microhábitat, un hogar utilizado por los diferentes tipos de ectoparásitos, estos se mueven entre el pelo, sobre y por debajo de la piel e incluso pueden vivir en cada uno de los pelos (aunque también existen otros que no son parásitos y que sólo se alimentan de descamaciones de la piel).

Podemos encontrar una enorme cantidad de organismos sobre la piel que encuentran cobijo en el pelo, por ejemplo, en los humanos, los ácaros viven enterrados junto a los folículos pilosos donde consiguen alimento y pareja, sus zonas predilectas son las mejillas y la llamada "zona T", es decir, el área ocupada por la frente y la nariz. Es preciso remarcar que los humanos no somos los únicos portadores de ácaros, por ejemplo, en una búsqueda de garrapatas asociadas con el murciélago, encontramos ácaros de la misma familia (Demodicidae) en los párpados de estos mamíferos (ver imagen 1). 
Imagen 1. Ácaro de la familia Demodicidae. Fotografía: Angel Herrera Mares

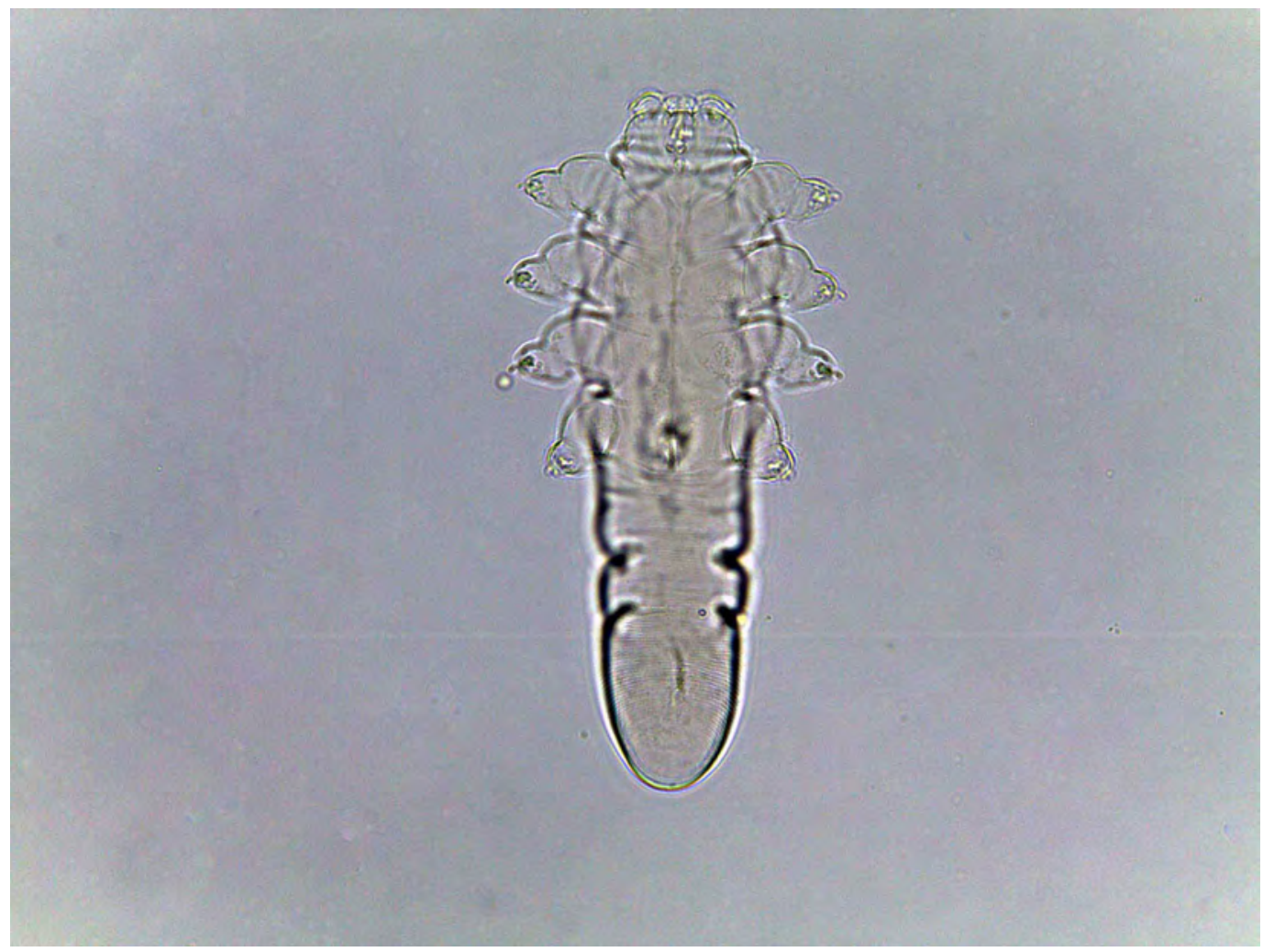

Por otro lado, las pulgas presentan unas estructuras en forma de peinetas (ctenidios) en la cabeza y en el tórax que les facilita el movimiento entre el pelaje. El número y forma de estas estructuras está relacionado con la cantidad de pelo de sus huéspedes. Por ejemplo, la pulga del gato, Ctenocephalides felis, presenta un par de estas estructuras que le permiten moverse con mayor facilidad a través del abundante pelaje del gato, mientras, la pulga del humano, Pulex irritans, carece de estas estructuras ya que, en comparación con los gatos, los humanos somos lampiños.

Es probable que el lector comience a rascarse la cabeza al leer estas líneas, pues existe otro grupo de ectoparásitos que pasan toda su vida sujetándose del pelo por medio de sus uñas, los piojos. Estas uñas pueden variar de grosor dependiendo del grosor del pelo del huésped. Por ejemplo, los humanos pueden presentar dos especies de piojos, los típicos que viven en la cabeza y las ladillas ubicadas en el vello púbico (y a veces otros lugares). Sin necesidad de ver una fotografía, el lector se puede imaginar cuál de las dos especies tiene las uñas más gruesas.

Además, los piojos no sólo se encuentran en los primates, también se han encontrado otro tipo de especies alrededor de la cabeza, el cuello y las axilas de los elefantes (Sudan et al., 2015) y en la unión entre el dorso y las patas traseras de los leones marinos (Ebmer et al., 2019). Aparte, es importante considerar que debido al escaso pelo de algunos mamíferos, como en los rinocerontes, algunos 
"Parásitos y pelos: historias de la selva de Chamela" Carmen Guzmán Cornejo y Angel Herrera Mares Vol. 22, Núm. 3, mayo-junio 2021 Revista Digital Universitaria

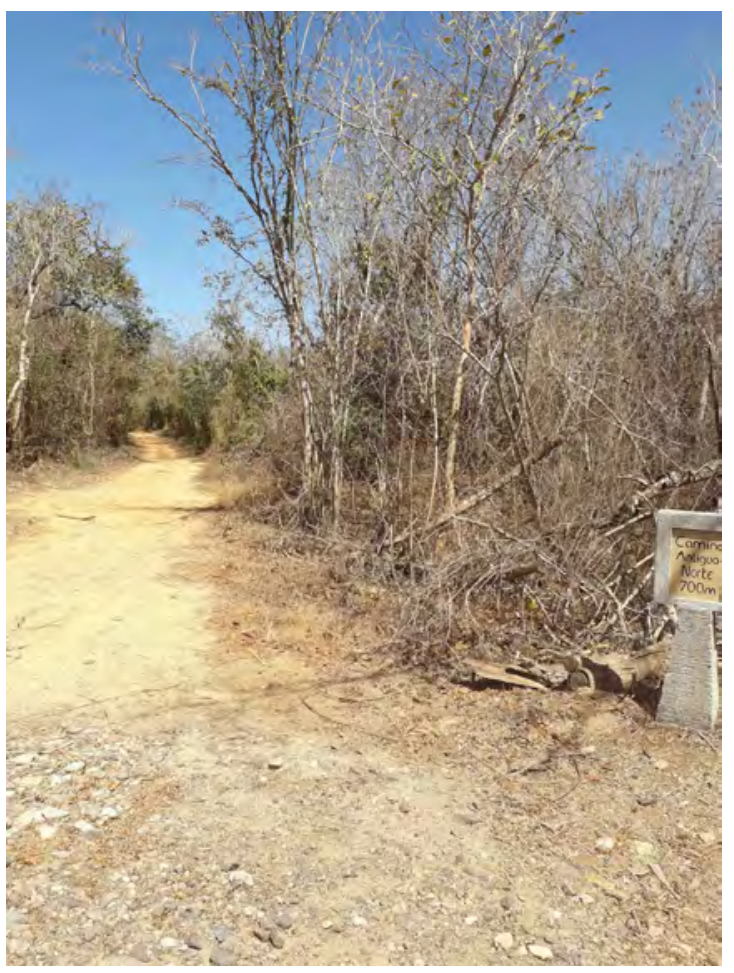

Imagen 2. Estación de Biología Chamela, Jalisco, México. Abril, 2018. Fotografía: Carmen Guzmán Cornejo

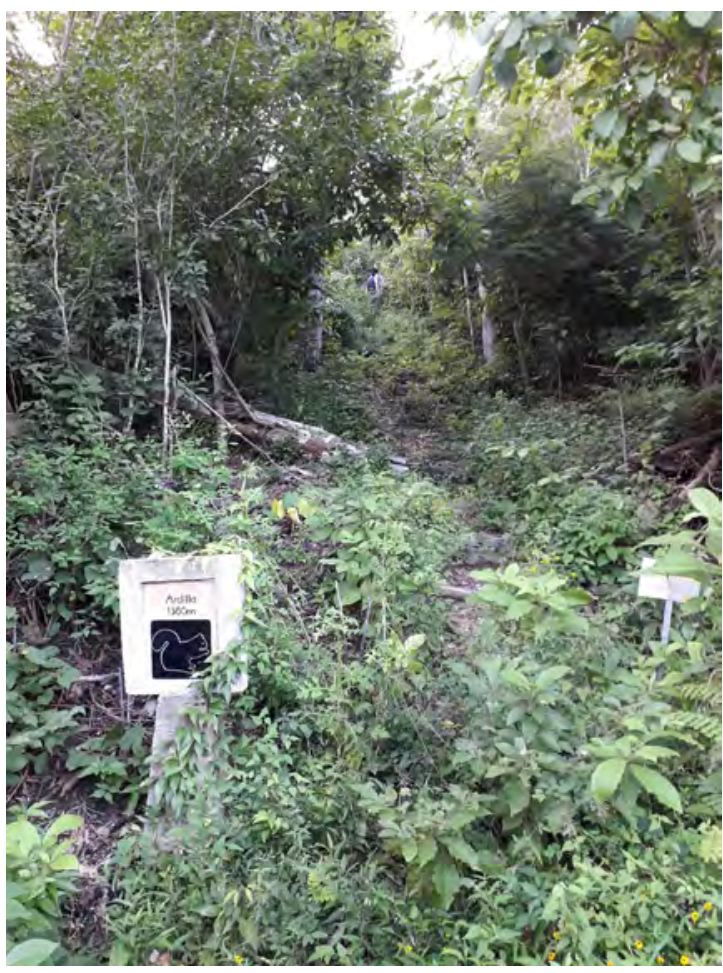

Imagen 3. Estación de Biología Chamela, Jalisco, México. Noviembre, 2018. Fotografía: Carmen Guzmán Cornejo parásitos buscan sitios poco comunes para esconderse, algo así sucede en las garrapatas de la especie Cosmiomma hipopotamensis, estas suelen vivir alrededor y dentro del ano del rinoceronte negro (Horak et al., 2018).

\section{Un día en la selva, en busca de ectoparásitos}

A pesar de que el parasitismo es una de las formas de vida más comunes en la naturaleza, los parásitos pocas veces son considerados como parte de la diversidad biológica del planeta. En este sentido, actualmente, miembros del Laboratorio de Acarología de la Facultad de Ciencias de la Universidad Nacional Autónoma de México (UNAM) realizamos un proyecto de investigación en la Estación de Biología Chamela, ubicada en Jalisco, México, con el objetivo de inventariar la fauna de ectoparásitos asociada con mamíferos pequeños y medianos. Este proyecto surgió al percatarnos de que la información disponible sobre los ectoparásitos en la región de Chamela estaba incompleta, a pesar de que la Estación fue fundada hace más de 40 años.

El viaje hasta este lugar es pesado, no sólo por el tiempo que nos toma llegar sino por tener que transportar todo el material necesario para trabajar en el campo. A pesar del cansancio, la Estación nos recibe con paisajes maravillosos, aunque dependen de la época del año en la que nos encontremos, por ejemplo, durante la temporada de secas, la selva baja tiene un aspecto muerto, pero es el sonido de los carpinteros y las chachalacas que nos recuerdan que sí hay vida en ese lugar (ver imagen 2). Por otro lado, durante la temporada de lluvias, la selva se ve verde y llena de vida (ver imagen 3).

Pero, sin importar cual sea la época del año, el equipo tiene que trabajar. Así, el primer día colocamos unas trampas por los senderos de la estación. Al siguiente, muy temprano, vamos a revisarlas para evitar que los mamíferos atrapados se sofoquen por la salida del sol. Cada revisión de las trampas es una moneda al aire, pues lo que cayó puede ser algún mamífero, alguna ave intrusa como el cerquero oliváceo, o un travieso coatí que provocó su cierre al aventarlas.

De manera general, cada mamífero es cepillado y revisado con ayuda de unas pinzas de punta fina y de peines piojeros. Los roedores son más fáciles de manipular por su 
tamaño pequeño, al igual que los tlacuaches, por su estrategia de hacerse los muertos, pero en el caso de los coatíes y los ocelotes estos tienen que sedarse, procedimiento realizado por un médico veterinario, y una vez dormidos, el equipo, en completo silencio, procede a buscar parásitos por todo su cuerpo.

Los ectoparásitos no sólo son encontrados entre el pelo de los huéspedes, algunos de ellos esperan pacientemente su alimento en el ambiente, como es el caso de las garrapatas. Si uno presta atención a la vegetación de Chamela, podemos ver a estos organismos sobre las hojas de algunas plantas (ver imagen 4). Y para evitar el trabajo de buscarlas hoja por hoja, se puede imitar el cruzar de los animales por los diferentes senderos de la Estación, al pasar una manta blanca sobre la vegetación baja. Cada cierto tiempo y distancia, la manta se revisa y las garrapatas atrapadas en la trampa son colectadas.

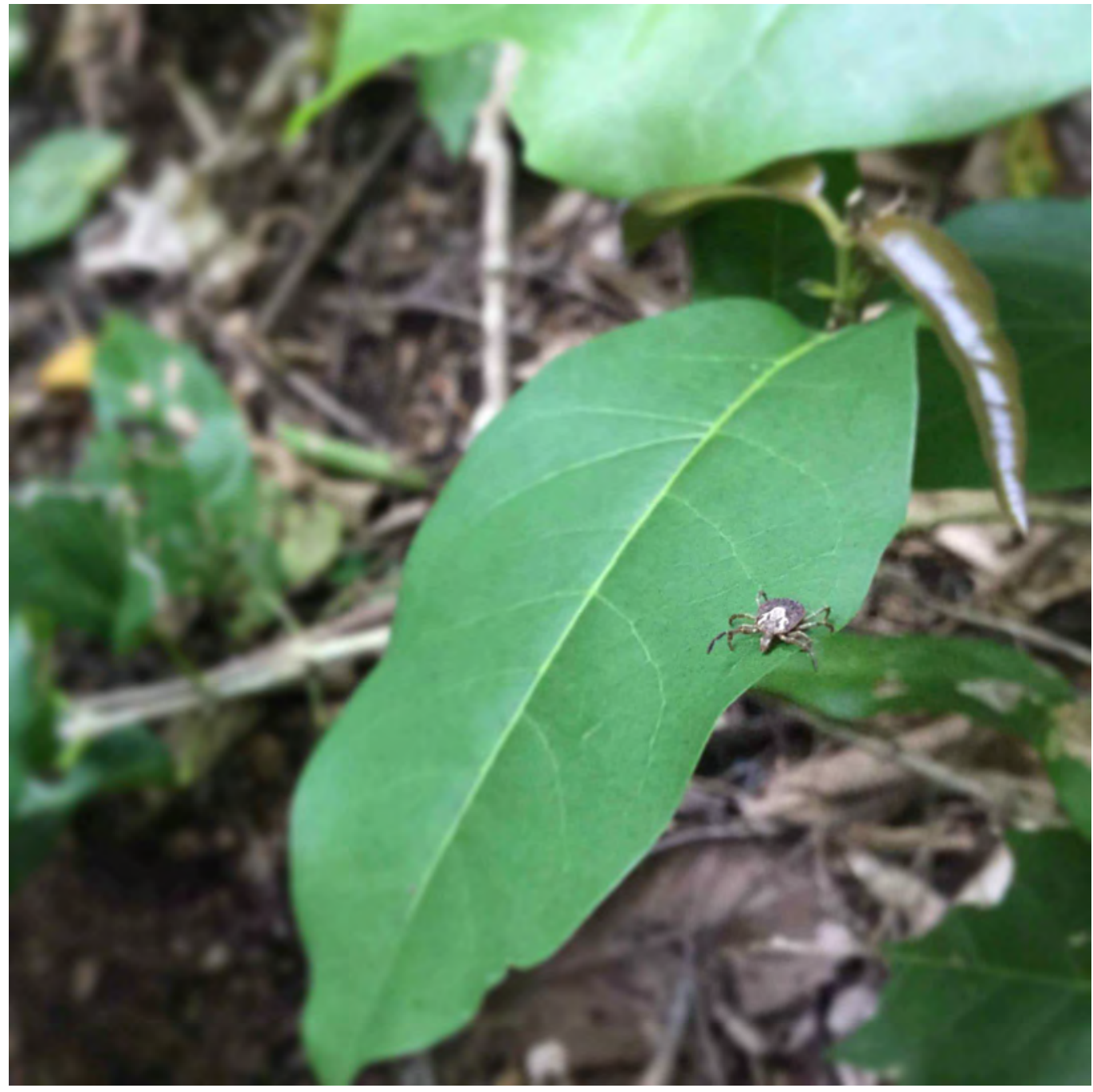

Tristemente, otra forma de obtener muestras de ectoparásitos es a través de animales atropellados. La Estación se encuentra sobre la carretera Manzanillo- 
"Parásitos y pelos: historias de la selva de Chamela" Carmen Guzmán Cornejo y Angel Herrera Mares Vol. 22, Núm. 3, mayo-junio 2021 Revista Digital Universitaria

Puerto Vallarta. Algunas veces salimos muy temprano a caminar sobre ella, y en estos recorridos logramos encontrar mamíferos como los mapaches, que no lograron caer en nuestras trampas. Sin importar la forma en la que logramos conseguir las muestras, todos los parásitos recolectados son puestos en viales con alcohol para ser estudiados en el Laboratorio de Acarología, donde son separados, sexados y determinados taxonómicamente.

\section{¿Qué hemos encontrado?}

Hasta este momento, visitamos la Estación de Biología Chamela en cuatro ocasiones, dos en temporada de secas (abril) y dos a finales de lluvias (noviembre). De estas cuatro salidas al campo se han colectado 105 roedores de 5 especies, 9 carnívoros de 3 especies, 1 conejo de la especie Sylvilagus cunicularius y 15 tlacuaches de la especie Didelphis virginiana. De todos estos huéspedes obtuvimos 8076 artrópodos: 7021 ácaros, 789 garrapatas, 230 piojos y 36 pulgas. Muchos de ellos los encontramos moviéndose activamente sobre el cuerpo de los mamíferos y otros sólo vivían de una manera más sedentaria, sujetándose de la piel o del pelo. Aunque muchos de estos organismos son verdaderos parásitos que se alimentan de la sangre o de los líquidos de los tejidos de sus huéspedes, hay otros que no lo son, por ejemplo, los llamados comensales, que se alimentan de las descamaciones de la piel (Hoffmann, 2003).

Para ejemplificar lo anterior, en noviembre de 2018, recolectamos más de 1900 ácaros de la especie Leporacarus sylvilagi en el pelo de un solo conejo (ver imagen 5K). Este tipo de ácaros viven agarrados de los pelos, gracias a la modificación de su primer y segundo par de patas, lo cual les permiten embonar con el pelo del conejo. Estos ácaros no son parásitos sino comensales.

Otro ejemplo es el del piojo Neotrichodectes pallidus (ver imagen 5A), especie asociada con los coatíes que viven en la Estación, en un individuo logramos obtener 143 piojos. A diferencia de los ácaros del ejemplo anterior, estos insectos se alimentan del pelo, sin embargo, se sabe que en números más altos pueden causar dermatitis o infecciones secundarias.

Aunque recolectamos garrapatas en la vegetación de los senderos de las Estación, los coatíes y los tlacuaches fueron los únicos mamíferos que presentaron las cuatro especies de garrapatas conocidas hasta este momento. Probablemente, sea porque estos animales recorren grandes distancias en busca de alimento y, en su paso por la vegetación, son aprovechados por las garrapatas (ver imagens 5B-C, 5E-F). Un descubrimiento interesante ocurrió durante el segundo año de colectas (2019), cuando cayó un ocelote en una de las trampas y pudimos encontrarle garrapatas, pulgas y la especie de piojo Felicola (Lorisicola) cf. felis (ver imagens 5F-H), la cual representó el primer registro para México (Guzmán-Cornejo et al., 2019). 
Imagen 5. Algunos ectoparásitos encontrados sobre mamíferos en la Estación de Biología Chamela, Jalisco.

1) Nasua narica (coatí), 2)

Didelphis virginiana (tlacuache),

3) Leopardus pardalis (ocelote),

4) Heteromys pictus (roedor), 5) Sylvilagus cunicularius (conejo). A) Neotrichodectes pallidus (piojo) B) Amblyomma mixtum (garrapata), C) Amblyomma ovale (garrapata),

D) Ornithonyssus wernecki (ácaro) E) Amblyomma cf. oblongoguttatum (garrapata), F) Amblyomma parvum (garrapata),

G) Pulex porcinus (pulga), $\mathrm{H}$ ) Felicola (Lorisicola) cf. felis (piojo), I) Steptolaelaps liomydis (ácaro), J) Geomylichus postscutatus (ácaro),

K) Leporacarus sylvilagi (ácaro). Fotografías: Carmen Guzmán Cornejo y Ana Isabel Bieler.

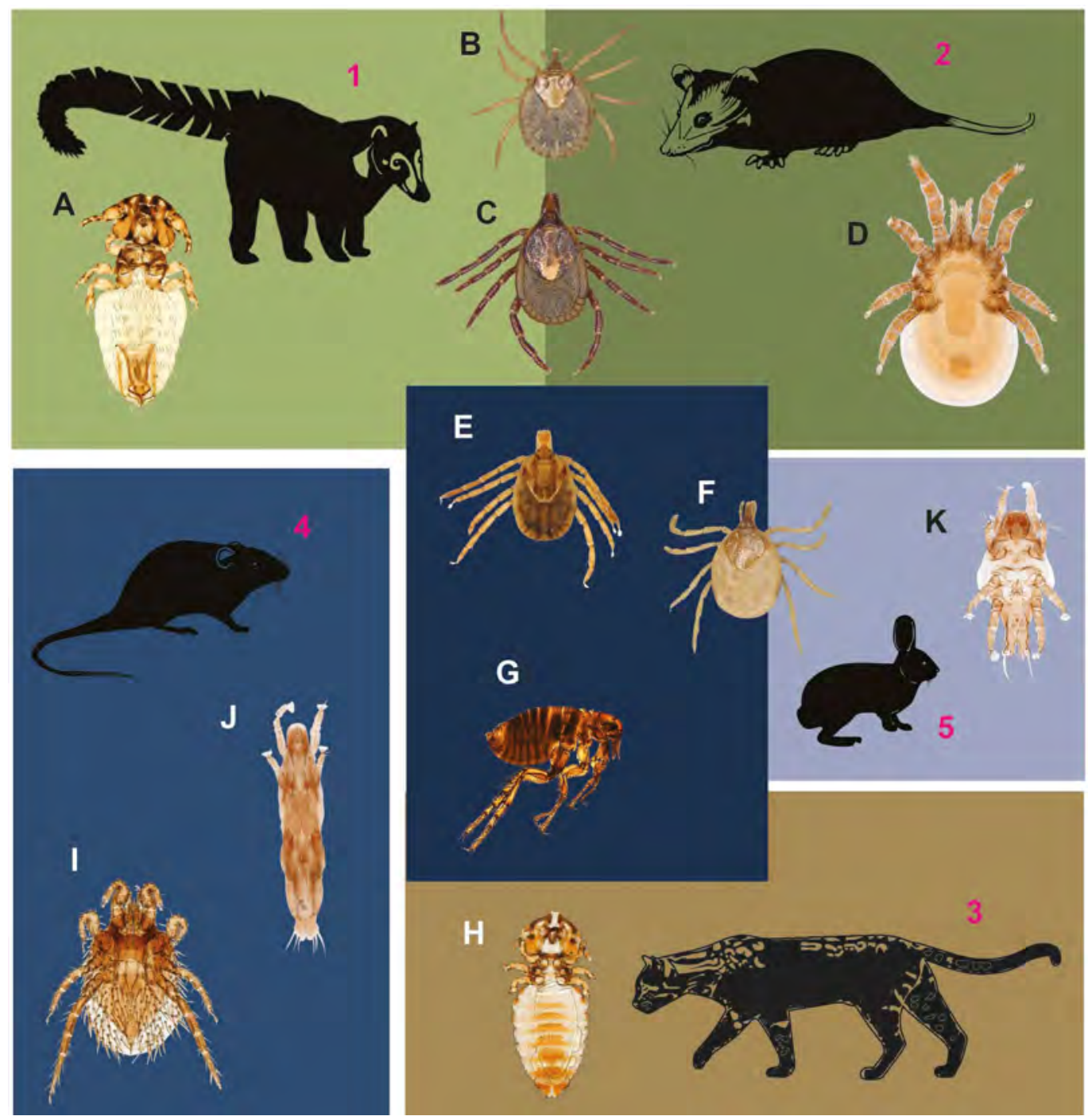

\section{Un oasis por explorar}

Durante este proyecto tuvimos la oportunidad de revisar varias especies de mamíferos y a pesar de hacerlo en un corto periodo de tiempo, durante dos años, hemos aumentado el número de especies de artrópodos asociados en la Estación de 22 a 38. Aunque aún faltan muchos grupos de mamíferos por revisar, como murciélagos, musarañas, pecaríes, venados, e incluso algunas especies de ratones que viven en otros lugares, como en la copa de los árboles.

Por otro lado, la Estación representa un sitio para la búsqueda de ectoparásitos en otros grupos de vertebrados como aves, anfibios y reptiles ya que se sabe poco sobre los ciclos de vida de los parásitos, pero es probable que varios grupos de vertebrados están interviniendo en ellos. Por ejemplo, en general, las aves funcionan como huéspedes de los estados juveniles de las garrapatas y es probable que algunas especies, como las chachalacas, tengan 
"Parásitos y pelos: historias de la selva de Chamela" Carmen Guzmán Cornejo y Angel Herrera Mares Vol. 22, Núm. 3, mayo-junio 2021 Revista Digital Universitaria

un papel importante en el mantenimiento de su ciclo de vida. Sin embargo, para lograr investigar estos casos, hace falta tiempo y proyectos financiados que apoyen este tipo de investigaciones.

Después de tanta información quizá el lector se esté preguntando ¿para qué sirve un parásito? Los parásitos pueden funcionar como reguladores de poblaciones de sus huéspedes ya que cuando las infestaciones son altas o cuando pueden transmitir microorganismos causantes de enfermedades, eliminan a los huéspedes débiles o susceptibles, manteniendo una población sana. Aunque en realidad, lo más importante, como lo mencionamos con anterioridad, es que forman parte de la diversidad biológica dentro de un ecosistema.

En este sentido, otra de nuestras líneas de investigación es la detección de bacterias de importancia médica-veterinaria asociadas con artrópodos hematófagos. Hasta el momento hemos logrado detectar la presencia de especies de bacterias del género Rickettsia por medio de técnicas moleculares. Este tipo de bacterias, pueden llegar a ser un problema de salud pública, como lo es la especie Rickettsia rickettsii, transmitida por la garrapata del perro y que, en Mexicali, México, causó muertes en humanos (Tinoco-Gracia et al., 2018). En Chamela, una de las especies más comunes es Rickettsia amblyommatis, cuya patogenicidad no es muy clara (Ulloa et al., 2019). Al igual que los ectoparásitos no todas las bacterias son peligrosas, muchas de ellas forman parte de la microbiota de las garrapatas y pueden servir como reguladoras de las que sí son peligrosas, sin embargo, esta línea de investigación aún se explora.

\section{Ambiente y taxonomía, dos crisis}

Actualmente, debido a la crisis ambiental y a la pérdida de diversidad biológica acelerada, el surgimiento de nuevas enfermedades no es algo inesperado, ya que cada vez es mayor el contacto entre los animales silvestres, los domésticos y el humano. Muchas de estas enfermedades también son resultado del desconocimiento sobre los parásitos, los huéspedes y los agentes causales que pueden existir en una determinada región.

De manera general, cuando se detecta el brote de alguna enfermedad desconocida o poco estudiada, lo primero por hacer es determinar al agente etiológico, es decir, al organismo que causa la enfermedad, ya sea a través de su observación directa bajo un microscopio o de manera indirecta a través de diferentes técnicas de laboratorio (como la prueba de antígeno-anticuerpos, PCR, para detectar el SARS-COV-2). Y, si se trata de una especie nueva, se tendría que nombrar, describir y publicar para darla a conocer y para que todos tengan acceso a la información.

Este trabajo apasionante, lo realiza un profesional cuya formación requirió seguramente de varios años y con una especialidad en taxonomía o en sistemática del grupo con el que trabaja. La taxonomía o la sistemática es la rama 
de la biología que se encarga de describir, nombrar y clasificar a las especies. Desafortunadamente a pesar de su importancia, con frecuencia este tipo de estudios recibe poco apoyo para su desarrollo.

Aunado a la crisis ambiental, la taxonomía por sí misma tiene su propia crisis, pocos estudiantes muestran interés en esta área, lo que provoca una disminución en el número de especialistas, particularmente en invertebrados. En el caso de muchas reservas, los inventarios de especies de vertebrados están muy cerca de completarse, pero esto no es así para muchos grupos de invertebrados, como los artrópodos, debido a la falta de especialistas y de apoyo para la realización de proyectos.

Si, además, agregamos una tercera crisis, la económica, es hora de ver los proyectos de manera integral, en donde las colaboraciones con gente comprometida de varias disciplinas ayuden a conocer, entender y atender algunas problemáticas derivadas de la crisis ambiental. Consideramos que la Estación de Chamela es un buen sitio para poner en práctica lo anterior y es una región que permitirá, a futuro, seguir contando historias más allá del pelo.

\section{Referencias}

* Ebmer, D., Navarrete, M. J., Muñoz, P., Flores, L. M., Gärtner, U., Taubert, A. y Hermosilla, C. (2019). Antarctophthirius microchir infestation in synanthropic South American sea lions (Otaria flavescens) males diagnosed by a novel non-invasive method. Parasitology Research, 118(5), 1353-1361. https://doi.org/10.1007/s00436019-06273-2

* Guzmán-Cornejo, C., Herrera-Mares, A., Ugalde-Medina, A., López-Pérez, A. M., Del Castillo-Martínez, L., Acosta-Gutiérrez, R., Cabrera-Garrido, M. y MoralesMalacara, J. B. (2019). Arthropods associated with mammals. Their importance as part of the richness in a Biosphere Reserve in Mexico. Journal of Medical Entomology, 57(3), 780-787. https://doi.org/10.1093/jme/tjz237

* Horak, I. G., Heyne, H., Williams, R., Gallivan, G. J., Spickett, A. M., Bezuidenhout, J. D. y Estrada-Peña, A. (2018). The Ixodid ticks (Acari: Ixodidae) of Southern Africa. Springer. https://doi.org/10.1007/978-3-319-70642-9

- Hoffmann, A. (2003). Animales desconocidos: relatos acarológicos. (3. ${ }^{\text {a ed.). Fondo }}$ de Cultura Económica.

* Martin, R. E., Pine, R. H. y DeBlase, A. F. (2011). A manual of Mammalogy with keys to

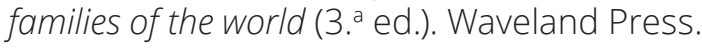

* Sudan, V., Jaiswal, A. K., y Shanker, D. (2015). A rare documentation of Haematomyzus elephantis lice from elephants of Mathura. Journal of parasitic diseases: official organ of the Indian. Society for Parasitology, 39(4), 793-794. https://doi.org/10.1007/ s12639-014-0424-8 
* Tinoco-Gracia, L., Lomelí, M., Hori-Oshima, S., Stephenson, N., y Foley, J. (2018). Molecular confirmation of Rocky Mountain Spotted Fever epidemic agent in Mexicali, Mexico. Emerging Infectious Diseases, 24(9), 1723-1725. https://dx.doi. org/10.3201/eid2409.171523

* Ulloa, A., Bermúdez, S., Rosario-Cruz, R., Garcia-Rejon, J. E., y Baak-Baak, C. (2019). Rickettsiosis en México, revisión y estado actual del género Rickettsia en el país. En Algunas Enfermedades Infecciosas en México: Morbilidad y Mortalidad (pp. 19-40). Universidad Autónoma de Chiapas.

\section{Agradecimientos}

A la Dirección General de Asuntos del Personal Académico-Universidad Nacional Autónoma de México a través del Programa de Apoyo a Proyectos de Investigación e Innovación Tecnológica (PAPIIT, IN214918). Al personal de la Estación de Biología Chamela, Instituto de Biología, unAm por permitirnos el uso de sus instalaciones. Al equipo de trabajo: Laura Del Castillo, Martín Cabrera, Ana Ugalde, Andrés López, Jonathan López, Belem Isaak, José Luis Muciño, Gerardo Contreras y Andrea Rebollo. A Julieta Vargas Cuenca por la determinación taxonómica del conejo.

\section{Cómo CITAR ESTE ARTículo}

* Guzmán Cornejo, Carmen y Herrera Mares, Angel. (2021, mayo-junio). Parásitos y pelos: historias de la selva de Chamela. Revista Digital Universitaria (RDU), 22(3). http://doi.org/10.22201/cuaieed.16076079e.2021.22.3.2 